\title{
Application of Amplified Restriction Fragment Length Polymorphism for Genetic Characterization of Colletotrichum Pathogens of Alfalfa
}

\author{
Nichole R. O’Neill, Peter van Berkum, Jhy-Jhu Lin, Jonathan Kuo, George N. Ude, \\ William Kenworthy, and James A. Saunders
}

First, second, and seventh authors: USDA, ARS, Beltsville, MD 20705; third and fourth authors: Life Technologies, Inc., 8717 Grovemont Circle, Gaithersburg, MD; fifth and sixth authors: Department of Agronomy, University of Maryland, College Park 20742. Accepted for publication 8 April 1997.

\begin{abstract}
O’Neill, N. R., van Berkum, P., Lin, J. J., Kuo, J., Ude, G. N., Kenworthy, W., and Saunders, J. A. 1997. Application of amplified restriction fragment length polymorphism for genetic characterization of Colletotrichum pathogens of alfalfa. Phytopathology 87:745-750.

Amplified restriction fragment length polymorphism (AFLP) was used to assess the levels of genomic variations among species and isolates of the genus Colletotrichum. Our objective was to characterize at the molecular level two alfalfa pathogens, isolates Arl-NW and 57RR, which are unusually aggressive to anthracnose-resistant alfalfa cultivars and whose taxa has been uncertain based on morphological criteria. The fingerprint patterns obtained were complex but did enable us to place these two isolates within the species $C$. trifolii and $C$. gloeosporioides, respectively. The

morphic DNA analyses. Similarity matrices generated with three primer pairs were highly correlated and, thus, were combined to determine the similarity among the fungal species and isolates that were analyzed. Analysis of the data generated with each of the primer pairs individually and application of either distance or parsimony methods supported the placement of these two isolates. The parsimony method of data analysis was more confirmatory in the placement of Phoma medicaginis as an outgroup than the distance method, using either simple matching or Jaccard's coefficients to generate the similarity matrices. Our conclusion is that the AFLP technique will be useful for identification of individual isolates within complex genera such as Colletotrichum because of its ability to generate large numbers of polymorphisms and the consistency of polymerase chain reaction amplification.
\end{abstract} diversity detected with AFLP among and within Colletotrichum species from alfalfa and other crops corroborated their published taxonomy based on morphology, ribosomal DNA sequence, and random amplified poly-
Additional keywords: DNA fingerprinting, Medicago sativa, PCR.

Recently, two unusual isolates of Colletotrichum (isolates ArlNW and 57RR) were identified as highly virulent to specific cultivars of alfalfa with genes for resistance to anthracnose (14). Based on cultural characteristics and spore morphology, isolates Arl-NW and 57RR resembled C. trifolii Bain \& Essary and $C$. gloeosporioides (Penz.) Penz. \& Sacc., respectively. However, isolate Arl-NW was unusually virulent and had narrower conidia than the other 16 C. trifolii isolates examined (14). Also, Arl-NW was highly aggressive to resistant cultivars but not to some normally susceptible cultivars, such as Saranac. Isolate 57RR was unusual because it was highly virulent to anthracnose-resistant alfalfa germplasm and exhibited a spore size within the range of C. trifolii rather than C. gloeosporioides. Therefore, the classification of isolate 57RR as C. gloeosporioides was questionable, because this species had not been reported previously as a pathogen of alfalfa and, unlike $C$. trifolii, rarely formed setae. The cultural characteristics of 57RR were similar to C. gloeosporioides, which was described as a group or a composite species by Sutton (20), in which considerable morphological and pathogenic variation is present (9). Thus, it generally is recognized that this taxa probably contains several species and that at present our understanding of the species is incomplete. Sutton (21) indicated that no progress in the genetic relationships and identification of phytopathogenic fungi was likely if based on morphology alone. Reliance on morphology or cultural characteristics for species determination and identification is difficult, because the characteristics of isolates often may change widely under varying conditions, affecting, for instance, pigmentation, size and structure of the acervuli and length and septation of setae.

A significant improvement in identification and classification of phytopathogenic fungi has come from restriction fragment length polymorphism (RFLP), polymerase chain reaction (PCR)-based
Publication no. P-1997-0509-01R

This article is in the public domain and not copyrightable. It may be freely reprinted with customary crediting of the source. The American Phytopathological Society, 1997 
random amplified polymorphic DNA (RAPD), and ribosomal DNA (rDNA) sequence analyses $(6,18,25,27)$. A limitation to RFLP analysis is the difficulty in standardization, the requirement of a great deal of operator time and effort, the variation in sensitivity, the amount of DNA required, the relatively small numbers of polymorphisms generated, and the extrapolation of genetic relationships based on variation of small, discrete regions of the chromosomes. Another technique uses PCR to produce RAPD markers. These are generated with short DNA primers and PCR. These markers are generated easily, and analyses are rapid, using only small amounts of DNA. However, preferential amplification of DNA fragments can mask relatedness between taxa or populations and limit reproducibility (26). Another method for analysis of DNA sequences is based on the rDNA repeat unit (6). Sequence analysis within the large ribosomal subunit are useful in distinguishing closely related taxa. In a number of fungi, sequence comparisons in two regions of the large ribosomal subunit, domain 2, and the internal transcribed spacers (ITS-1 and ITS-2) show the percent sequence variation in a range useful for phylogenetic comparisons (6).

Several molecular systematic studies that used RFLP, rDNA, and RAPD analyses have been reported for Colletotrichum. Fingerprints generated with RAPD analysis with four primers permitted reliable differentiation between isolates of 10 species of Colletotrichum (4). New species groupings in the genus were proposed based on rDNA sequence analysis, and a clear relationship between morphological data and molecular analysis was demonstrated (19). RFLP techniques have been used to distinguish between forms of $C$. gloeosporioides and $C$. graminicola (18). Therefore, DNA-based methodology can provide valuable information about Colletotrichum populations and taxonomy (10).

Amplified restriction fragment length polymorphism (AFLP) is a recently reported PCR-based technique for generating molecular markers that has been used with plants, bacteria, and nematodes $(5,7,24)$. This technique also has been used to analyze symbiotic fungi cultured by the fungus-growing ant Cyphomyrmex minutus (12). In this technique, genomic DNA is digested with two restriction endonucleases, and the fragments are ligated to specific single-stranded oligonucleotide adapters. The restriction fragments are amplified selectively by PCR with primers containing selective nucleotides homologous to the adapters, with 1- to 3-bp ex- tensions at the $3^{\prime}$ end. DNA fragments complimentary to the extensions are amplified selectively, separated on a polyacrylamide gel, and visualized by autoradiography. In contrast to RAPD techniques, AFLP uses sequence-specific primers, which eliminates the variability associated with nonspecific primers. The AFLP technique is powerful because it generates numerous DNA fragments from nanogram quantities of DNA, and reaction conditions are stringent, which improves reproducibility. AFLP DNA mapping was more useful than RFLP and RAPD techniques in identifying molecular markers in soybean (8). Coupled with segregation analyses, AFLP should be useful for determining the genetic and molecular basis of biological phenomena in phytopathogenic fungi, such as race/cultivar specificity and virulence.

The purpose of the current study was to evaluate and apply the AFLP technique to phytopathogenic fungi and define the genetic relationship between $C$. trifolii and the two highly aggressive Colletotrichum isolates causing anthracnose in alfalfa. Phoma medicaginis Malbr. \& Roum., another Coelomycete that is pathogenic to alfalfa, was chosen as an outgroup.

\section{MATERIALS AND METHODS}

Fungal isolates and morphology. Fungal isolates were obtained from a collection maintained by N. O'Neill at Beltsville, $\mathrm{MD}$, and from G. Wiedeman, University of Arkansas, Fayetteville. The origin and morphological characteristics of the Colletotrichum isolates are given in Tables 1 and 2. Spores from isolates were stored on silica gel crystals at $4^{\circ} \mathrm{C}$. Spores were produced on half-strength oatmeal agar (36 g of Difco [Detroit] oatmeal agar, 1 liter of distilled water, and $7.5 \mathrm{~g}$ of agar) incubated for 7 days at $22^{\circ} \mathrm{C}$ under $12 \mathrm{~h}$ of fluorescent light (15). Spores were scraped from the agar surface, suspended in sterile distilled water, and placed on a depression slide for 12 to $24 \mathrm{~h}$ at $20^{\circ} \mathrm{C}$. Spores were examined for morphology and the presence or absence of a septum in spores that had germinated and produced appressoria, using a Zeiss (Thornwood, NY) universal microscope equipped with Nomarski optics. The mean length and width of spores was determined by measuring at least 200 spores per isolate, using an image analysis system (Loates Associates, Inc., Westminster, MD).

Isolation of genomic DNA. Mycelia were collected by vacuum filtration from $200 \mathrm{ml}$ of Czapek-Dox broth cultures (Difco) inoc-

TABLE 1. Host and origin of Colletotrichum spp. characterized by amplified restriction fragment length polymorphism

\begin{tabular}{|c|c|c|c|c|c|c|}
\hline Lane $^{\mathrm{a}}$ & Species & $\begin{array}{c}\text { Isolate } \\
\text { designation }\end{array}$ & Host plant & $\begin{array}{c}\text { Conidial } \\
\text { spore shape }\end{array}$ & Septation $^{\mathrm{b}}$ & Origin \\
\hline 1 & C. trifolii, race 1 & 271 & Medicago sativa & Ovoid & $\mathrm{N}$ & MD \\
\hline 2 & C. trifolii, race 1 & $3-5$ & Medicago sativa & Ovoid & $\mathrm{N}$ & MD \\
\hline 3 & C. trifolii, race 1 & TpRe1 & Trifolium pratense & Ovoid & $\mathrm{N}$ & MD \\
\hline 4 & C. trifolii, race 1 & $2 \mathrm{sp} 2$ & Medicago sativa & Ovoid & $\mathrm{N}$ & MD \\
\hline 5 & C. trifolii, race 1 & Arl-NW & Medicago sativa & Ovoid & $\mathrm{N}$ & WI \\
\hline 6 & C. trifolii, race 2 & $\mathrm{~S} 1-1$ & Medicago sativa & Ovoid & $\mathrm{N}$ & MD \\
\hline 7 & C. trifolii, race 2 & 586 & Medicago sativa & Ovoid & $\mathrm{N}$ & MD \\
\hline 8 & C. trifolii, race 2 & 486 & Medicago sativa & Ovoid & $\mathrm{N}$ & MD \\
\hline 9 & C. lindemuthianum, race sigma & 1419 & Phaseolus vulgaris & Ovoid & $\mathrm{N}$ & Canada \\
\hline 10 & C. orbiculare & 683 & Cucumis sativus & Ovoid & $\mathrm{N}$ & AR \\
\hline 11 & C. gloeosporioides & $57 \mathrm{RR}$ & Medicago sativa & Ovoid & $\mathrm{Y}$ & MD \\
\hline 12 & C. gloeosporioides & C129 & Lycopersicon esculentum & Ovoid & $\mathrm{Y}$ & VA \\
\hline 13 & C. gloeosporioides f. sp. aeschynomene & 662 & Aeschynomene virginica & Ovoid & $\mathrm{Y}$ & AR \\
\hline 14 & C. coccodes & C9 & Lycopersicon esculentum & Ovoid & $\mathrm{Y}$ & MD \\
\hline 15 & C. coccodes & $\mathrm{C} 4$ & Lycopersicon esculentum & Ovoid & $\mathrm{Y}$ & MD \\
\hline 16 & C. coccodes & C111 & Solanum tuberosum & Ovoid & $\mathrm{Y}$ & PA \\
\hline 17 & C. fragariae & 383 & Fragaria ananassa & Ovoid & $\mathrm{Y}$ & LA \\
\hline 18 & C. acutatum, nonchromogenic form & 1118 & Malus sylvestris & Ovoid & $\mathrm{Y}$ & AR \\
\hline 19 & C. sublineolum & 1062 & Sorghum bicolor & Falcate & $\mathrm{Y}$ & AR \\
\hline 20 & C. capsici & 991 & Gossypium sp. & Falcate & $\mathrm{Y}$ & LA \\
\hline 21 & C. dematium & 685 & Medicago sativa & Falcate & $\mathrm{Y}$ & GA \\
\hline 22 & C. dematium & 785 & Medicago sativa & Falcate & $\mathrm{Y}$ & GA \\
\hline 23 & Phoma medicaginis & $\mathrm{T} 431$ & Medicago sativa & $\ldots$ & & \\
\hline
\end{tabular}

a Refers to lane in Figure 1.

${ }^{\mathrm{b}}$ Indicates presence or absence of a septum produced after conidial germination. 
ulated with a spore suspension and incubated on a shaker at $23^{\circ} \mathrm{C}$ for 8 days. Mycelial mats were stored in vials at $-70^{\circ} \mathrm{C}$. DNA was extracted and purified as described by Rehner and Uecker (16).

AFLP analysis. AFLP assays were performed with AFLP Analysis System I (Life Technologies, Inc., Gaithersburg, MD) following the manufacturer's instructions and as described by Lin and Kuo (7). In AFLP, genomic DNA is digested by restriction endonucleases, ligated to EcoRI and MseI adapters, and amplified by $\mathrm{PCR}$, using primers that contain the common sequences of the adapters and one to three arbitrary nucleotides as selective sequences. The number of AFLP polymorphic bands produced in a single reaction is determined by the specificity of the restriction enzyme primers used to digest the genomic DNA, the number and choice of selective nucleotides at the $3^{\prime}$ end of the restriction enzyme primers, and the size and complexity of the plant genome being analyzed $(7,24)$.

Primary template DNA was prepared in a one-step restrictionligation reaction. Fungal genomic DNA (250 ng) was digested by EcoRI and $\mathrm{MseI}$ at $37^{\circ} \mathrm{C}$ for $2 \mathrm{~h}$ and heated to $70^{\circ} \mathrm{C}$ for $15 \mathrm{~min}$ to inactivate the enzymes. The DNA fragments were ligated to EcoRI and $\mathrm{Mse}$ I adapters provided in the kit for $2 \mathrm{~h}$ at $20^{\circ} \mathrm{C}$. After terminating the reaction, the ligation mixture was diluted 10 -fold with sterile distilled water, and the fragments were preamplified by 20 PCR cycles. The preselective amplification was performed in a PE-9600 thermal cycler (Perkin-Elmer Cetus, Norwalk, CT), using a temperature profile of $94^{\circ} \mathrm{C}$ for $30 \mathrm{~s}, 56^{\circ} \mathrm{C}$ for $60 \mathrm{~s}$, and $72^{\circ} \mathrm{C}$ for $60 \mathrm{~s}$, as described by Vos et al. (24).

For selective amplification of restriction fragments, EcoRI selective primers with two selective nucleotides were used: EcoRI + $\mathrm{AG},+\mathrm{AT}$, or + TA. The effectiveness of each of these pairs was evaluated in combination with selective primer MseI + C. Selective primers were provided by Life Technologies. Preliminary experiments with combinations of one and three selective nucleotides with EcoRI resulted in the generation of either too many or too few amplified DNAs. For selective amplification, 5- $\mu$ l subsamples of the preamplified fragments were diluted 50-fold, and ${ }^{32} \mathrm{P}$-labeled EcoRI+2 and unlabeled $M s e \mathrm{I}+1$ primers were used. The PCR amplification temperature profile was one cycle at $94^{\circ} \mathrm{C}$ for $30 \mathrm{~s}, 56^{\circ} \mathrm{C}$ for $30 \mathrm{~s}$, and $72^{\circ} \mathrm{C}$ for $60 \mathrm{~s}$ and then the annealing temperature was lowered during each cycle by $0.7^{\circ} \mathrm{C}$ for 12 cycles. The remainder of the amplification was 23 cycles at $94^{\circ} \mathrm{C}$ for $30 \mathrm{~s}$, $56^{\circ} \mathrm{C}$ for $30 \mathrm{~s}$, and $72^{\circ} \mathrm{C}$ for $60 \mathrm{~s}$. The PCR products in $2.5-\mu \mathrm{l} \mathrm{sub}-$ samples were separated by electrophoresis, using a denaturing $5 \%$ (wt/vol) polyacrylamide DNA sequencing gel containing $7.5 \mathrm{M}$ urea. Autoradiographs were obtained by exposing Kodak BioMax MR-2 film (Eastman Kodak Co., Rochester, NY) to the dried gel with intensifying screens overnight at $-70^{\circ} \mathrm{C}$. Every experiment was repeated at least three times.

Data analysis. The autoradiographs produced with each of the three primer sets were scanned into a computer for analysis. The presence or absence of all bands between molecular sizes of 50 and 300 bp were scored in each of the 23 lanes by Proscore, version 2.02 (DNA Proscan, Inc., Nashville, TN). The resulting binary matrices were prepared for transformation by NTSYS-pc, version 1.60 (17), for derivation of simple matching or Jaccard's coefficients and for clustering analysis of the 23 fungal isolates and to compare the matrices obtained with the three individual sets of primers. The information obtained with each of the primers was compared by computing the product-moment correlation $(r)$, which is monotonically related to the Mantel test statistic $(Z)$, to measure the degree of relationship between each of the three similarity matrices obtained with the three sets of primers. The significance of the relationship between each of these three matrices was determined by comparing the observed $Z$ value with 1,000 random permutations of $Z$ in a one-tailed probability test. The similarity matrix data obtained with the three sets of primers were combined to determine the genetic relationship among the 23 fungal isolates. A dendrogram was constructed using the unweighted pair-group method with arithmetic average. Results from analyses using simple matching coefficients were compared with analysis using Jaccard's coefficient for pairwise comparisons.

The same data from each of the three primer pairs also was analyzed by the parsimony method, using the Dollop and polymorphism parsimony program, version 3.5c (3). Majority rule consensus trees were derived from bootstrapping 500 replications of the input matrices.

\section{RESULTS}

The total number of bands within the range of 50 to $300 \mathrm{bp}$ scored was 90, 108, and 105 for the AFLP analyses with primers EcoRI $+\mathrm{AG},+\mathrm{AT}$, or $+\mathrm{TA}$, respectively, in combination with $\mathrm{MseI}+\mathrm{C}$. The matrices with scores for the presence or absence of bands contained 2,070, 2,484, and 2,415 data points for these three primers sets, respectively. Repetitions using the same set of primers and fungal isolate consistently yielded similar polymorphic band numbers and patterns (data not shown). Different DNA preparations of the same isolate also yielded similar results. This reliable reproducibility was possible because primer annealing is very specific due to homology to both the adapter sequence and the restriction site sequence. Simple matching coefficients between Colletotrichum species and isolates were derived. Bands representing molecular sizes larger than $300 \mathrm{bp}$ were not scored in the analysis, because the resolution was insufficient to discriminate between bands of various molecular sizes (Fig. 1). Presumably, these bands could have been scored with additional runs of the primer sets and longer electrophoretic durations to increase the resolution. However, the 6,969 data points obtained from bands between 50 and $300 \mathrm{bp}$ and used for the analysis were adequate to determine the genetic relationships among the 23 fungal isolates. The product-moment correlations were $0.85,0.85$, and 0.79 in a comparison of the matrices obtained with the EcoRI + AG and

TABLE 2.Virulence and spore dimensions of isolates of Colletotrichum pathogenic to alfalfa

\begin{tabular}{|c|c|c|c|c|c|}
\hline \multirow[b]{2}{*}{ Species (isolate designation) } & \multirow[b]{2}{*}{ Race } & \multirow{2}{*}{$\begin{array}{c}\text { Host resistance } \\
\text { phenotype }\end{array}$} & \multicolumn{3}{|c|}{ Spore measurements $(\mu)^{\mathrm{b}}$} \\
\hline & & & Length & Width & Ratio \\
\hline C. trifolii (271) & 1 & $\mathrm{An}_{1}$ & 9.4-(10.6)-11.9 & $5.9-(6.8)-8.1$ & 0.64 \\
\hline C. trifolii (2sp2) & 1 & $\mathrm{An}_{1}$ & $8.6-(10.9)-13.2$ & $3.8-(4.2)-5.4$ & 0.39 \\
\hline C. trifolii $(\mathrm{TpRe} 1)$ & 1 & $\mathrm{An}_{1}$ & 7.8-(9.2)-11.8 & 3.4-(4.4)-5.4 & 0.48 \\
\hline C. trifolii (Arl-NW) & 1 & $\mathrm{An}_{1}$ & $7.8-(8.3)-9.8$ & $2.9-(3.4)-4.8$ & 0.41 \\
\hline C. trifolii $(\mathrm{S} 1-1)$ & 2 & $\mathrm{An}_{1}, \mathrm{An}_{2}$ & $11.9-(12.9)-15.3$ & $5.1-(5.6)-6.8$ & 0.43 \\
\hline C. gloeosporioides (57RR) & $\ldots$ & None & $10.6-(11.9)-13.4$ & $3.2-(4.5)-5.6$ & 0.38 \\
\hline
\end{tabular}

${ }^{a}$ Indicates the host resistance gene that is effective against the race designated. C. gloeosporioides isolate C129 is nonpathogenic to alfalfa; isolate 57RR is highly pathogenic to alfalfa cultivars with the $\mathrm{An}_{1}$ and $\mathrm{An}_{2}$ phenotypes $(13,14)$.

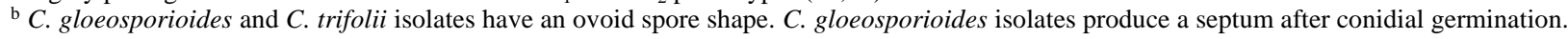


$E c o \mathrm{RI}+\mathrm{AT}$, the $E c o \mathrm{RI}+\mathrm{AG}$ and $E c o \mathrm{RI}+\mathrm{TA}$, and the $E c o \mathrm{RI}+$ $\mathrm{TA}$ and $E c o \mathrm{RI}+\mathrm{AT}$ primers, respectively, in combination with primer $\mathrm{Mse}+\mathrm{C}$. Of 1,000 permutations, the probability that the random $Z$ value was greater than or equal to the observed $Z$ was 0.001 . Because the matrices obtained with the individual primer sets were very similar, the genetic relationship among the 23 fungal isolates could have been determined from each alone.

A dendrogram produced from combined AFLP data from three primer pair sets was used to assess relatedness among isolates (Fig. 2). Our interpretation of these data is that isolates of the same species generally were more similar. The fingerprint patterns obtained with isolate Arl-NW were most similar to those of the isolates of $C$. trifolii races 1 and 2 (Fig. 1). The similarity matrix analysis indicated that Arl-NW was 98\% similar to isolates of C. trifolii. This result supports identification of this isolate as C. trifolii based on cultural characteristics and spore morphology.

1

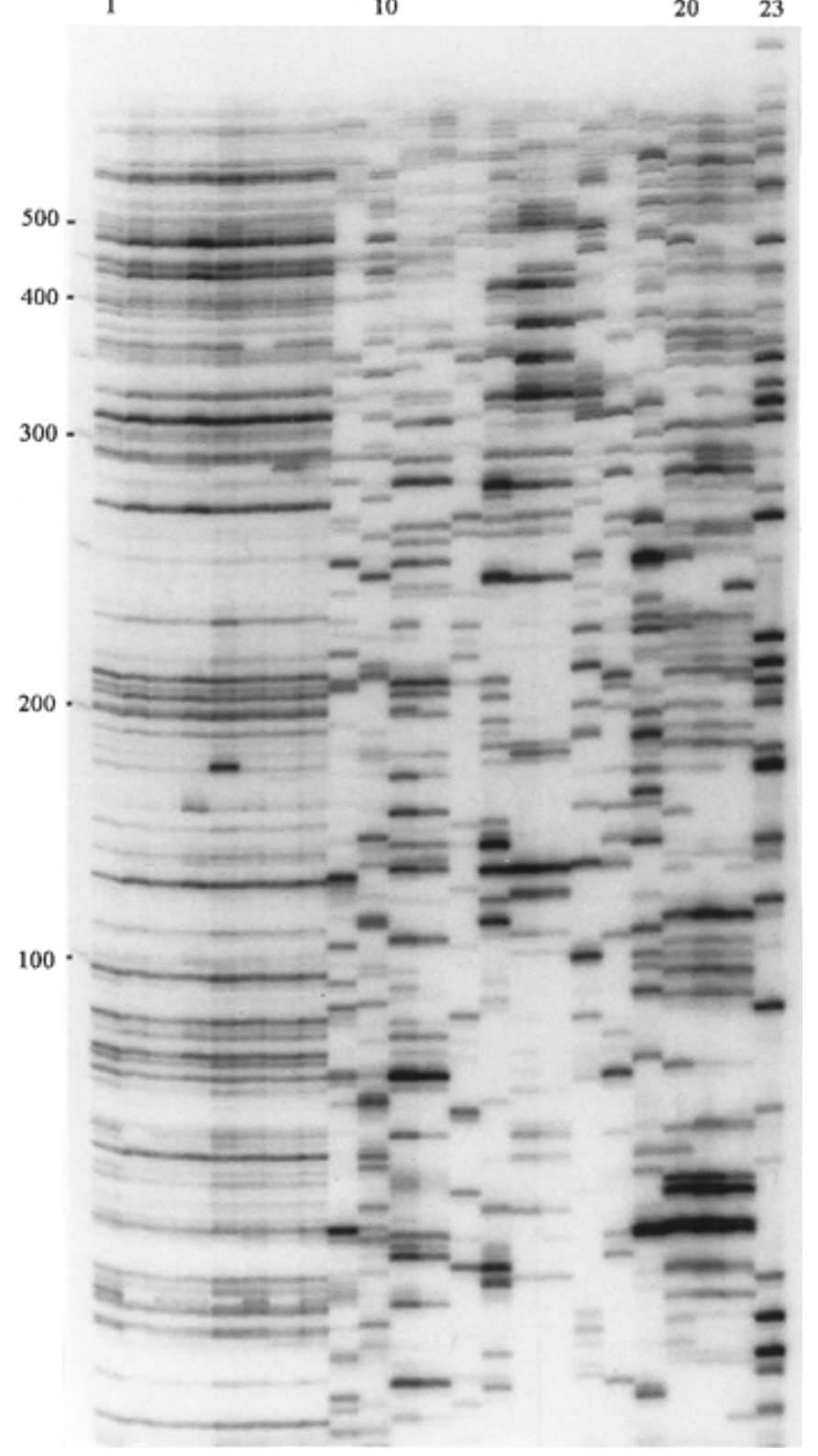

Fig. 1. Amplified fragment length polymorphism fingerprint of 22 species and isolates of Colletotrichum and 1 isolate of Phoma medicaginis after selective amplification with one primer combination (EcoRI + AG and $\mathrm{Mse} \mathrm{I}+\mathrm{C}$ ). Lanes 1 through 23 represent the fungal species and isolates encoded in Table 1. Molecular weights are indicated in base pairs to the left. Bands between 300 and 50 bp were scored.
The intraspecific variation among isolates of $C$. trifolii was very small. Race-specific markers were not identified with the primer sets used.

Isolate 57RR consistently clustered with isolate C129, supporting its placement in C. gloeosporioides. With the exception of $C$. dematium and C. capsici, all isolates were more than $65 \%$ similar. These species exhibited similar morphologies and were $85 \%$ similar. Greater than $90 \%$ similarity was seen in three pairs of isolates of the same species. Unexpectedly, P. medicaginis, included in this study as an unrelated fungus, was more than $70 \%$ similar to the Colletotrichum species.

Isolates clustered similarly regardless of whether the data was analyzed by Jaccard's or simple matching coefficients. However, the distance analysis method using Jaccard's coefficient resulted in much longer branch lengths (data not shown). Genetic similarities of most isolates occurred between 0.5 and $40 \%$, in contrast to the similarities between 55 and $75 \%$ generated by simple matching coefficients (Fig. 2).

The results of cluster analysis of Colletotrichum species, using the parsimony method and the same three primer pairs, were similar to results obtained by simple matching coefficients (Fig. 3). Data sets from primer pairs AG and AT resulted in a dendrogram

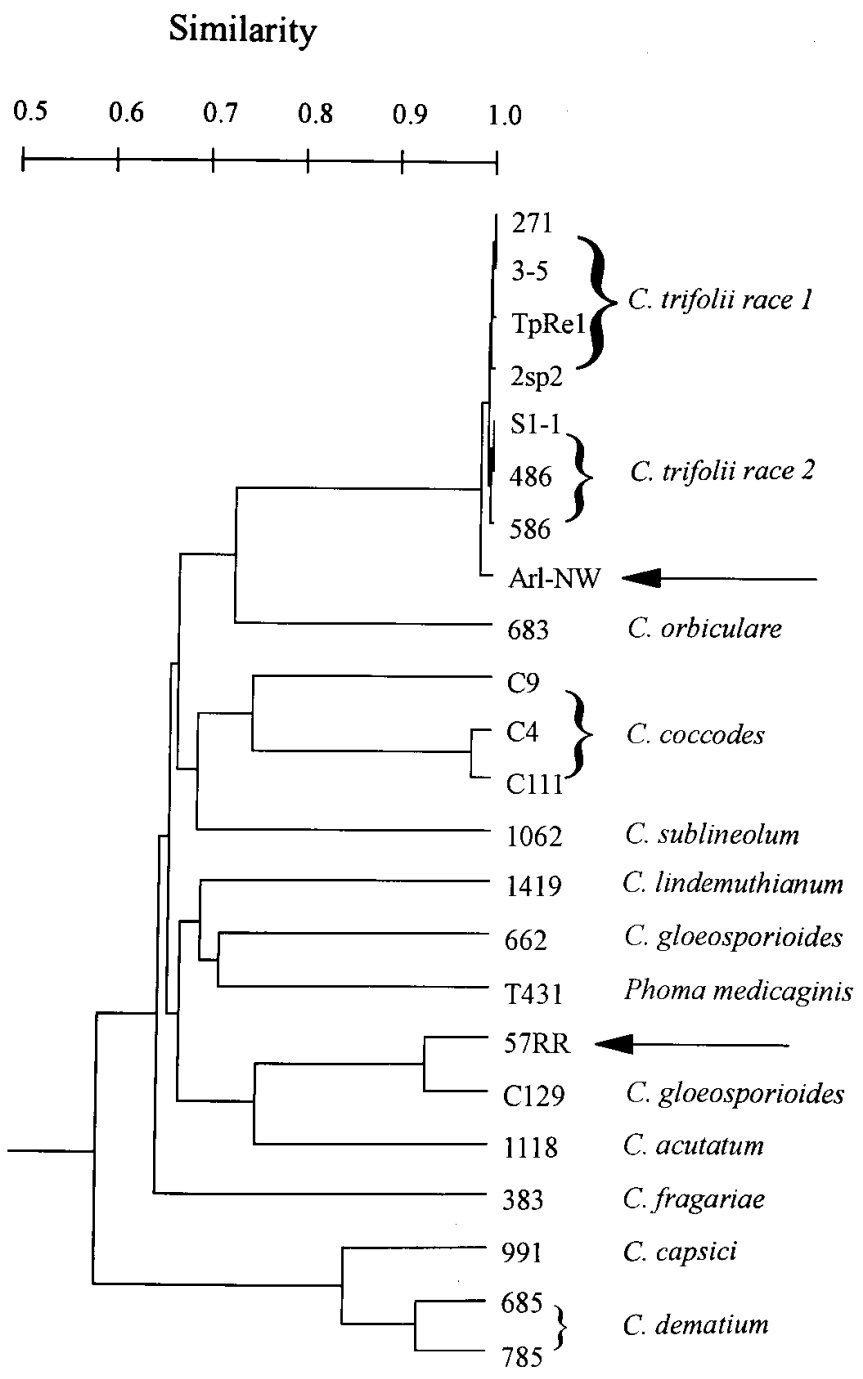

Fig. 2. Similarity dendrogram of 22 species and isolates of Colletotrichum and 1 isolate of Phoma medicaginis based on the presence or absence of amplified fragment length polymorphism fragments. The matrix was generated by combining the data from three selective nucleotide primer pair combinations, using simple matching coefficients. EcoRI selective primers with two selective nucleotides $(E c o \mathrm{RI}+\mathrm{AG},+\mathrm{AT}$, or $+\mathrm{TA})$ were used in combination with selective primer $M s e \mathrm{I}+\mathrm{C}$. 
that most closely matched relationships between species and isolates that would be predicted by morphological criteria. $C$. trifolii isolates, including Arl-NW, clustered tightly and also included $C$. orbiculare, which has been proposed to be conspecific with $C$. trifolii. C. gloeosporioides isolate 57RR clustered with C129, three $C$. coccodes isolates clustered, and $C$. dematium isolates clustered and were close to the morphologically similar species $C$. capsici. In addition, $P$. medicaginis did not cluster with any of the Colletotrichum isolates. Results of cluster analysis using parsimony and polymorphic bands from primer pair TA were more variable.

\section{DISCUSSION}

The taxonomic placement of isolates 57RR and Arl-NW is uncertain based solely on classical criteria of spore morphology, size, and host pathotype. The results of the current study indicate that isolate Arl-NW is more closely associated with $C$. trifolii than with any other species. Isolate 57RR consistently grouped with C. gloeosporioides isolate C129. Because C. gloeosporioides is not considered a well-defined species, it is not surprising that the third isolate of this species did not similarly cluster. These conclusions were supported by distance analyses with simple matching and Jaccard's coefficients, as well as by parsimony analysis.

The morphology of the isolates used in this study was consistent with their original identifications and with current taxonomic criteria (21). Species with similarly shaped ovoid conidia that do not exhibit a septum when germinated include $C$. trifolii races 1 and 2, C. lindemuthianum, $C$. orbiculare, and $C$. malvar- um (not examined here). On the basis of conidial morphology, this group was considered by von Arx (23) to be forms of C. gloeosporioides. Later, their species designation was based on host specificity. More recently, this group has been distinguished from other species with similar conidial morphologies on the basis of rDNA sequence analysis (19). A further indication that the isolates in this group may be closely related to each other is that they share a similar pattern of lectin binding (13). They also exhibit a similar initial infection process (intracellular growth of infection vesicles and hyphae and hemibiotrophic hyphal growth), except that $C$. trifolii does not appear to exhibit a biotrophic phase (1). The results of the current study indicate a close association between $C$. trifolii isolates and an isolate of $C$. orbiculare but not between these two species and an isolate of $C$. lindemuthianum. Cluster analysis of Colletotrichum isolates based on rDNA sequence analysis revealed that all Colletotrichum species examined were $93 \%$ similar and that the average within-group similarity for the four similar species (C. trifolii, $C$. orbiculare, C. malvarum, and $C$. lindemuthianum) was $99.6 \%$ (19). Further analysis by AFLP, which examines the whole genome, and a larger number of isolates of these four species will be useful to corroborate the proposal that isolates within this group represent a single species $(C$. orbiculare) with distinct host-specific forms (19). Because of the large numbers of polymorphisms that can be generated, AFLP may be well suited as a technique to identify markers associated with host specificities.

Species concepts in Colletotrichum are very broad, and physiological host specialization continues to be an important factor for
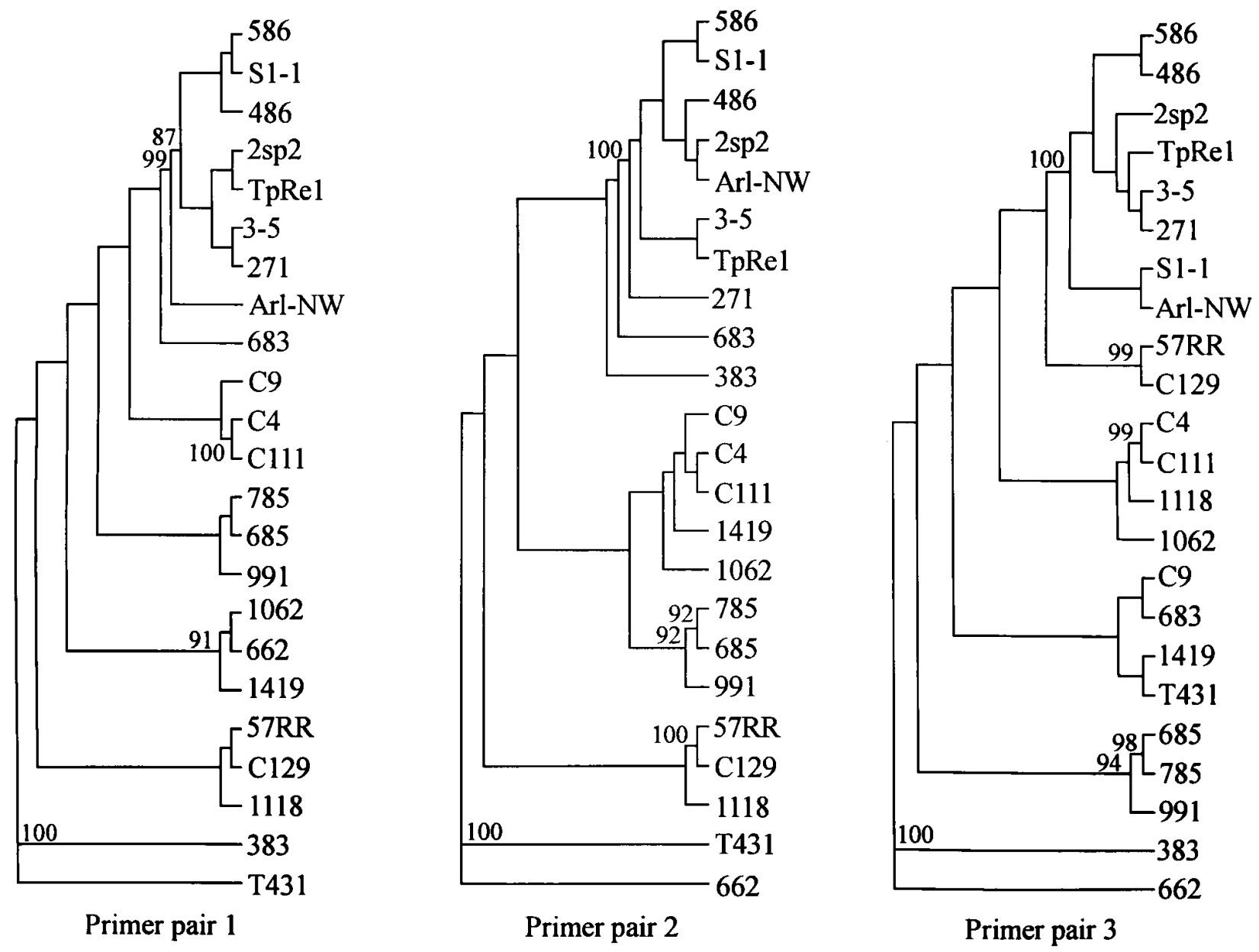

Fig. 3. Amplified fragment length polymorphism analysis of 22 Colletotrichum species and 1 isolate of Phoma medicaginis, using three selective nucleotide primer combinations. Parsimony consensus trees were constructed by comparing polymorphic bands generated from EcoRI primers with two selective nucleotides $(E c o \mathrm{RI}+\mathrm{AG},+\mathrm{AT}$, or $+\mathrm{TA})$ used in combination with selective primer MseI + C (primer pairs 1, 2, and 3, respectively). The number at each node represents the frequency of occurrence at that branch point based on an analysis with 500 replications. Branch lengths are not shown. 
identification. Moreover, morphological characters derived from growth of isolates in culture are inconsistent, and cultural conditions rarely have been standardized. Combined with the inherent phenotypic plasticity of individual isolates, authoritative identifications are difficult, especially within the composite species $C$. gloeosporioides. In addition to taxonomic considerations, clarification of species concepts in Colletotrichum is important for implementation of proper quarantine, trade, and disease control strategies. AFLP DNA fingerprinting may facilitate the identification of specific genes or linked polymorphisms associated with host specificity, race specificity, virulence, and avirulence. A molecular description of the genetic differences between fungal strains provides a basis for further investigation of mechanisms that generate genetic variation in fungi.

Using the AFLP technique, we have confirmed the taxonomic placement of two alfalfa pathogens and provided evidence that species of Colletotrichum can be distinguished. Three methods of data analysis resulted in generally similar dendrograms. An interesting difference between methods of analysis was that the outgroup isolate, $P$. medicaginis, was not grouped with Colletotrichum spp. when data were analyzed using the parsimony method and two of three primer pairs. A possible explanation for this result is that the parsimony method is more conservative than simple matching coefficients for PCR-based data, because it scores common bands divided by the total number of bands present in the two samples being compared. With this method, the shared absence of bands is not considered a similarity. Clustering of $P$. medicaginis with Colletotrichum also may have occurred, because of the large number of polymorphisms generated by AFLP, which would lead us to suggest that the technique may be most useful in determining genetic variation between species or isolates and may not be a valid technique to apply to intergenic variation. The use of a larger number of isolates and species in future studies should reveal levels of inter- and intraspecific variation in this genus.

The advantages of the AFLP technique compared to RAPD and RFLP analyses are that it is fast, is relatively inexpensive, is highly reproducible, generates a high frequency of AFLP polymorphisms, and requires only small quantities of DNA. However, results may vary depending on the method of analysis chosen. One limitation of PCR-based techniques such as AFLP is the chance that unrelated sequences with a similar size may be scored as "the same," resulting in an artificial amplification of the number of similar bands. This problem may be compounded with the AFLP technique when a large number of bands are scored within a limited size range. Nevertheless, AFLP DNA analysis is an attractive technique for investigating genetic diversity among isolates and species within complex fungal genera such as Colletotrichum.

\section{ACKNOWLEDGMENTS}

We thank M. Blum for excellent technical assistance.

\section{LITERATURE CITED}

1. Bailey, J. A., O'Connell, R. J., Pring, R. J., and Nash, C. 1992. Infection strategies of Colletotrichum species. Pages 88-120 in: Colletotrichum: Biology, Pathology and Control. J. A. Bailey and M. J. Jeger, eds. CAB International, Oxford.

2. Farr, D. F., Bills, G. F., Chamuris, G. P., and Rossman, A. Y. 1989. Fungi on Plants and Plant Products in the United States. The American Phytopathological Society, St. Paul, MN.

3. Felsenstein, J. 1993. PHYLIP (phylogenetic inference package). Version 3.5c. Department of Genetics, University of Washington, Seattle.

4. Freeman, S., Pham, M., and Rodriguez, R. J. 1993. Molecular geno- typing of Colletotrichum species based on arbitrarily primed PCR, A + T-rich DNA, and nuclear DNA analyses. Exp. Mycol. 17:309-322.

5. Folkertsma, R. T., Rouppe van der Voort, N. A. M., de Groot, K. E., van Zandvoort, P. M., Schots, A., Gommers, F. J., Helder, J., and Bakker, J. 1996. Gene pool similarities of potato cyst nematode populations assessed by AFLP analysis. Mol. Plant-Microbe Interact. 9:47-54.

6. Hillis, D. M., and Dixon, M. T. 1991. Ribosomal DNA: Molecular evolution and phylogenetic inference. Q. Rev. Biol. 66:411-453.

7. Lin, J. J., and Kuo, J. 1995. A novel PCR-based assay for plant and bacterial DNA fingerprinting. Focus 17:66-70.

8. Lin, J. J., Kuo, J., Ma, J., Saunders, J. A., Beard, H. S., MacDonald, M. H., Kenworthy, W., Ude, G. N., and Matthews, B. F. 1996. Identification of molecular markers in soybean comparing RFLP, RAPD, and AFLP DNA mapping techniques. Plant Mol. Biol. Rep. 14:156-169.

9. Manners, J. M., Masel, A., Braithwaite, K. S., and Irwin, J. A. G. 1992. Molecular analysis of Colletotrichum gloeosporioides pathogenic on the tropical pasture legume Stylosanthes. Pages 250-268 in: Colletotrichum: Biology, Pathology and Control. J. A. Bailey and M. J. Jeger, eds. CAB International, Oxford.

10. Mills, P. R., Hodson, A., and Brown, A. E. 1992. Molecular differentiation of Colletotrichum gloeosporioides isolates infecting tropical fruits. Pages 269-288 in: Colletotrichum: Biology, Pathology and Control. J. A. Bailey and M. J. Jeger, eds. CAB International, Oxford.

11. Mitchelmore, R. W., and Hulbert, S. H. 1987. Molecular markers for genetic analysis of phytopathogenic fungi. Annu. Rev. Phytopathol. 25:383404.

12. Mueller, U. G., Lipari, S. E., and Milgroom, M. G. 1996. Amplified fragment length polymorphism (AFLP) fingerprinting of symbiotic fungi cultured by the fungus-growing ant Cyphomyrmex minutus. Mol. Ecol. 5:119-122.

13. O'Connell, R. J., Nash, C., and Bailey, J. A. 1992. Lectin cytochemistry: A new approach to understanding cell differentiation, pathogenesis and taxonomy in Colletotrichum. Pages 67-87 in: Colletotrichum: Biology, Pathology and Control. J. A. Bailey and M. J. Jeger, eds. CAB International, Oxford.

14. O'Neill, N. R. 1996. Pathogenic variability and host resistance in the Colletotrichum/Medicago sativa pathosystem. Plant Dis. 80:450-457.

15. O'Neill, N. R., Elgin, J. H., Jr., and Baker, C. J. 1989. Characterization of induced resistance to anthracnose in alfalfa by races, isolates, and species of Colletotrichum. Phytopathology 79:750-756.

16. Rehner, S. A., and Uecker, F. A. 1995. Nuclear ribosomal internal transcribed spacer phylogeny and host diversity in the coelomycete Phomopsis. Can. J. Bot. 72:1666-1674.

17. Rohlf, J. F. 1990. NTSYS-pc: Numerical Taxonomy and Multivariate Analysis System. Version 1.60. Exeter Software, Setauken, NY.

18. Samuels, G. J., and Siefert, K. A. 1995. The impact of molecular characters on systematics of filamentous ascomycetes. Annu. Rev. Phytopathol. 33:37-67.

19. Sherriff, C., Whelan, M. J., Arnold, G. M., Lafay, J.-F., Brygoo, Y., and Bailey, J. A. 1994. Ribosomal DNA sequence analysis reveals new species groupings in the genus Colletotrichum. Exp. Mycol. 18:121-138.

20. Sutton, B. C. 1980. The Coelomycetes: Fungi Imperfecti with Pycnidia, Acervuli and Stromata. Commonwealth Mycological Institute, Kew, Surrey, England.

21. Sutton, B. C. 1992. The Genus Glomerella and its anamorph Colletotrichum. Pages 1-26 in: Colletotrichum: Biology, Pathology and Control. J. A. Bailey and M. J. Jeger, eds. CAB International, Oxford.

22. Tiffany, L. H., and Gilman, J. C. 1954. Species of Colletotrichum from legumes. Mycologia 46:52-75.

23. von Arx, J. A. 1957. Die Arten der Gattung Colletotrichum Corda. Phytopathol. Z. 29:413-468.

24. Vos, P. R., Hogers, M., Bleeker, M., Van de Lee Reijans, T., Hornes, M., Fritjers, A., Pot, J., Peleman, J., Kuiper, M., and Zabeau, M. 1995 AFLP: A new concept for DNA fingerprinting. Nucleic Acids Res. 23:4407-4414.

25. Welch, J., and McClelland, M. 1990. Fingerprinting genomes using PCR with arbitrary primers. Nucleic Acids Res. 18:7213-7218.

26. Wilkerson, R. C., Parsons, T. J., Albright, D. G., Klein, T. A., and Braun, M. J. 1993. Random amplified polymorphic DNA (RAPD) markers readily distinguish cryptic mosquito species (Diptera: Culicidae: Anopheles). Insect Mol. Biol. 1:205-211.

27. Williams, J. G. K., Kubelik, A. R., Livak, K. J., Rafalski, J. A., and Tingey, S. 1990. DNA polymorphisms amplified by arbitrary primers are useful as genetic markers. Nucleic Acids Res. 18:6531-6535. 